\title{
lga Batog
}

\section{Black Box Music by Simon Steen- Andersen: The Visual Layer as a Sound- Determining Factor. An Exploration of Prospects for Development}

\section{Abstract}

The article attempts to summarise the work of Simon Steen-Andersen and describe his composition titled Black Box Music in the context of fusing visual and musical experiences. I have examined how modern technology influences the composer's creative process. His achievements and understanding of audiovisuality and the music object have also been compared with Pierre Schaeffer's concept of acousmatic listening.

\section{Keywords}

audiovisuality, Simon Steen-Andersen, Black Box Music, music object 
The Italian Classic Voice magazine's invitation (addressed to a hundred music critics, musicologists, conductors, and festival organisers, excluding composers) to list the most important compositions created after 2000 resulted in two charts of the most highly appreciated works and their authors, printed in the monthly's January 2017 issue. The top three pieces on this list were: 1) Georg Friedrich Haas' In Vain, 2) Simon Steen-Andersen's Piano Concerto, 3) Stefan Prins' Generation Kill. Steen-Andersen himself came second among the most interesting contemporary music composers, ${ }^{1}$ His works, like those of Prins, represent a similar 'visual trend' in new music, depending on the perception of sound as part of a total sensory experience. In Black Box Music this is achieved through the use of theatrical elements; in Generation Kill - by means of game controllers, video projections, and live electronics.

\section{Simon Steen-Andersen. Life, Methodology, and Composition Techniques}

Simon Steen-Andersen (born in 1976), a composer, performer and installation artist, studied composition in 1998-2006 with Karl Aage Rasmussen, Mathias Spahlinger, Gabriel Valverde, and Bent Sørensen in Aarhus, Freiburg im Breisgau, Buenos Aires, and Copenhagen. He now teaches composition at the Royal Academy of Music (Det Jyske Musikkonservatorium) in Aarhus. Since 2013 he has also been a visiting professor at the Norwegian Academy of Music (Norges musikkhøgskole, NMH) in Oslo. He has collaborated with such leading contemporary music groups as Ensemble Intercontemporain, London Sinfonietta, Klangforum Wien, ICTUS, and Orkiestra Muzyki Nowej (New Music Orchestra). His works have been presented at the world's main new music festivals. His numerous accolades include the Sonning Music Foundation Talent Award (2006), the Kranichsteiner Musikpreis (2008), Award of the International Rostrum of Composers (2010), the Carl Nielsen Prize (2013), the Nordic Council Music Prize

For a full list of works and composers, see: Classic Voice, 212 (2017), http://www. classicvoice.com/riviste/classic-voice-digital/classic-voice-212-digitale.html, accessed 14 June 2020. 
(2014), the Carl Prisen Prize (2015), and the Mauricio Kagel Music Prize (2017). ${ }^{2}$

In my analysis of Simon Steen-Andersen's output, I will apply the criteria and refer to the methods of composition used in this composer's works. These criteria and methods have become progressively clearer in his successive compositions. For this reason, it seems worthwhile to preserve a certain chronology in my analyses of Andersen's output. Such an approach will make it possible to trace back a developing trend which came to the fore and reached its climax in Black Box Music.

\section{Methods of Composition and the Relation Between Traditional and Modern Media}

Steen-Andersen defines his method of composition as 'trying to come up with ideas first, and then looking for a suitable medium and material, and a suitable technology if needed'. ${ }^{3}$ His fascination with new technologies takes different forms. The composer makes frequent use of electronically amplified acoustic instruments in combination with a sampler, non-standard constructions of his own device, as well as everyday objects. He notes a certain analogy between the aesthetics and approaches of traditional and electronic music. For instance, when looking for a suitable way to perform a crescendo he draws on the dolly zoom electronic effect (zooming a lens to adjust the angle of view). In many of his works the nostalgic dimension of technology is brought out by the use of older generations of sound modifiers, such as the 1982 version of the Whammy pedal in Study for String Instruments \#2 or of a joystick controlling the divided screen in Run Time Error. These two compositions, written in 2007-2010, mark the beginning of a tendency to use unconventional and distinctly specific means.

\footnotetext{
2 The programme book of the $58^{\text {th }}$ 'Warsaw Autumn' International Festival of Contemporary Music, 2015, biographical note submitted by the composer, 269-270.

3 Simon Steen-Andersen - A musical approa[c]h to audio/visual composition: Implicit $A V$ aspects of musical performance, $A V$-objects and musical excuses..., Cursus de composition et d'informatique musicale de l'Ircam, Ircam, 5 Dec. 2018, https:// medias.ircam.fr/x13ea23, 1'18" - 1'35", accessed 10 Apr. 2021.
} 


\section{The Link Between Sampling and Quoting the Surrounding World}

Another field of interest for Steen-Andersen is the sampling technique, which appears in what is chronologically his next composition, Double Up (2010) for sampler and small orchestra. This piece exemplifies the technique of using pre-recorded sound samples and giving them new meanings and musical contexts. The work's dramaturgy is based on a simple sequence of everyday sounds played back from the sampler and doubled by the orchestra. The same sound sequence is presented from two different perspectives: narrative and musical. The former represents the semantic and informational potential of the sampled material. Snatches of sound information, such as the sound of toothbrushing, a shower, coffee maker, and a key turning in the door all add up to a coherent and comprehensible (even if slightly trivial) narration. The successive sounds organise auditory perception and give meaning to those that came before. This situation is reversed and rearranged in the second segment, in which the sounds are sorted by their acoustic potential and musical value, which allows the composer to present the same material from a new perspective.

Ouvertures, written in the same period, also makes use of a sampler, but this time as a medium for translating one selected cultural image into the language of music. Written for amplified guzheng solo, sampler and symphony orchestra, it incorporates a recording of Chinese dictator Mao Zedong's speech of 1956. Digitally slowed down and interwoven with the course of the music, the speech loses its political content while preserving the cultural context and musical qualities. It becomes, in a way, a song unfolding against the background of a guzheng and the orchestra. ${ }^{4}$

\section{Gesture: The Visual Aspect of Playing an Instrument, and Its Uses}

The physical aspect of playing an instrument is a recurring element of Steen-Andersen's music. The choreography of the sound production

\footnotetext{
Simon Steen-Andersen - A musical approa[c]h..., 19'51" - 24'11".
} 
process is for him a point of departure for comments on the subject of audiovisuality, that is, on the visual layer of music as a determinant of sound. The visual component of the concert experience is of fundamental sensory and form-building importance to the composer. It is out of an exploration of the shared visual-and-auditory space that his technique was born (and later improved over the years) of coordinating the visual and the auditory effect so that they mutually influence each other and form one whole. ${ }^{5}$ By working with elements taken from different fields of perception, the composer claims, we may attempt to superimpose them or oppose them to each other, but also look for the point of their perfect integration, where the two experiences interpenetrate.

The concert experience, Steen-Andersen notes, is always audiovisual (as long as our eyes remain open). It is only our habit of attributing a definite function for instance to the motion of the bow (necessary to produce sound) that makes us perceive movement exclusively as a way to achieve the goal of sound production. In this case, audiovisuality is thus a phenomenon of perception. If we adopt a conscious and open stance, the object may work in both categories towards a complete integration of auditory and visual elements or show the two from different angles. Many of Steen-Andersen's works explore pre-existent motion-and-sound setups and have been composed within certain set structures. This approach differs from theatricalization of instrument playing as proposed by instrumental theatre. The composer's cycle Studies for String Instrument \#1-3 (2007-2011) is dedicated in its entirety to the study of relations between sound and motion. The whole work is notated only as body movements and can therefore be performed on any bowed string instrument. ${ }^{6}$ The first piece in this cycle, Study \#1, can be described as a study of glissando. As the composer observes, the focus of a glissando is on the sound's movement from one point to another. Glissando therefore already contains 'movement of the sound' within itself, as experienced in auditory perception, as well as the aspect of the hand's actual movement along the string and

\footnotetext{
S. Steen-Andersen, Festival TACEC 2018, https://www.youtube.com/watch?v=PFSkfwRcviE\&t=33s, accessed 10 Apr. 2021.

6 The programme book of the $58^{\text {th }}$ 'Warsaw Autumn' International Festival of Contemporary Music, 2015, the composer's own commentary on Studies for String Instrument, 270.
} 
of the bow producing the sound. These two exemplify both aspects of audiovisuality. However, due to our knowledge of functions performed by the body movements, a glissando is usually only conceived as an articulation technique, subordinate to sound. In order to extend the visual perspective, the composer highlights and individualises the movement by frequent repetitions and tripling the number of instruments. At the same time, the rhythmic bow movements bestow a choreographic dimension on the work, forming a kind of self-accompanied dance.

The piece is also an exploration of the boundaries of motion-andsound structures and of the use of limited glissando material. To compose means, in this case, to explore the possibilities of one specific setup and gradually to extend it. Another example of such practice is Study \#3, where the cello, prepared by wetting the strings slightly and fixing pieces of paper to the bow, is later submitted to such experiments as turning the instrument to the side, while at the same time preserving the cello playing technique. Superimposed on the cello part is a pre-recorded version of the same musician's performance, which multiplies the visual perceptions. According to the composer, it was a challenge to create a given setup and then actively to study its possibilities. The resulting experience, though frequently not necessarily theatrical, nevertheless has its own internal sense and logic.

\section{Black Box Music}

Composed in 2012 for percussion, amplified box, fifteen performers and video, Black Box Music consists of three sections: Ouverture, Disambiguation, and Finale. The piece was originally written for Norwegian percussionist Håkon Stene.? The ensemble consists of baritone saxophone, bass clarinet, bassoon, horn, trumpet, trombone, piano, three sets of percussion instruments (including a güiro, an opera gong, sandpaper, a balloon, and slide whistle), as well as harp, electric guitar, viola, cello, and double bass. In his introduction to the score, the composer explains:

R. Holmboe, 'Out of the Box', liner notes for a DVD, Dacapo Records, https:// www.dacapo-records.dk/en/recordings/steen-andersen-black-box-music, accessed 10 Apr. 2021. 
The starting point is the classical soloist-conductor, only in this case, the conducting and solo part are one and the same. The setting is a traditional theatre stage with curtains, props and light; only in this case, the stage is also an instrument. Black Box Music could be said to be a deconstruction of conducting and puppet theatre as well as an exploration and exploitation of the audio/visual relations inherent in conducting and staging. ${ }^{8}$

The work reflects the composer's strong convictions concerning the link between conducting and the visual-choreographic aspects of the music work. The conductor's part may make the impression of a mere set of gestures performed in the air; nevertheless, these gestures have actual impact on the orchestra's sound. The cultural dimension of the conductor's role relates his gestures in our minds subconsciously to the orchestral part. His presence in the concert situation is not viewed as an attempt to make the music visual; however, as the composer emphasises, once a discrepancy between the conductor's gestures and the orchestra has occurred, this visual aspect becomes noticeable and clear.

Steen-Andersen reverses the traditional concert situation by dividing the orchestra into three groups and placing it on both sides of the audience as well as behind it. The eponymous black box is placed where the conductor would normally stand. The box is equipped with a camera and sound system consisting of six microphones connected to the corresponding speakers, which creates the topophonic effect of sound surrounding the audience.

The box also comes complete with a miniature curtain and a set of lights, which makes the whole look rather like a puppet show with an elaborate musical layer. The noise of a fabric strip pulled along rubber bands and the sound of the light switch are also treated as musical elements and precisely marked in the score. The protagonist of this peculiar spectacle, however, is the soloist, who at the same time acts as the conductor. He places his hands inside the box, while the image from the camera is projected onto a screen behind the box.

8 S. Steen-Andersen, Black Box Music (editor's materials), introduction to the score (2020), https://www.edition-s.dk/music/simon-steen-andersen/black-box-music, accessed 10 Apr. 2021. 


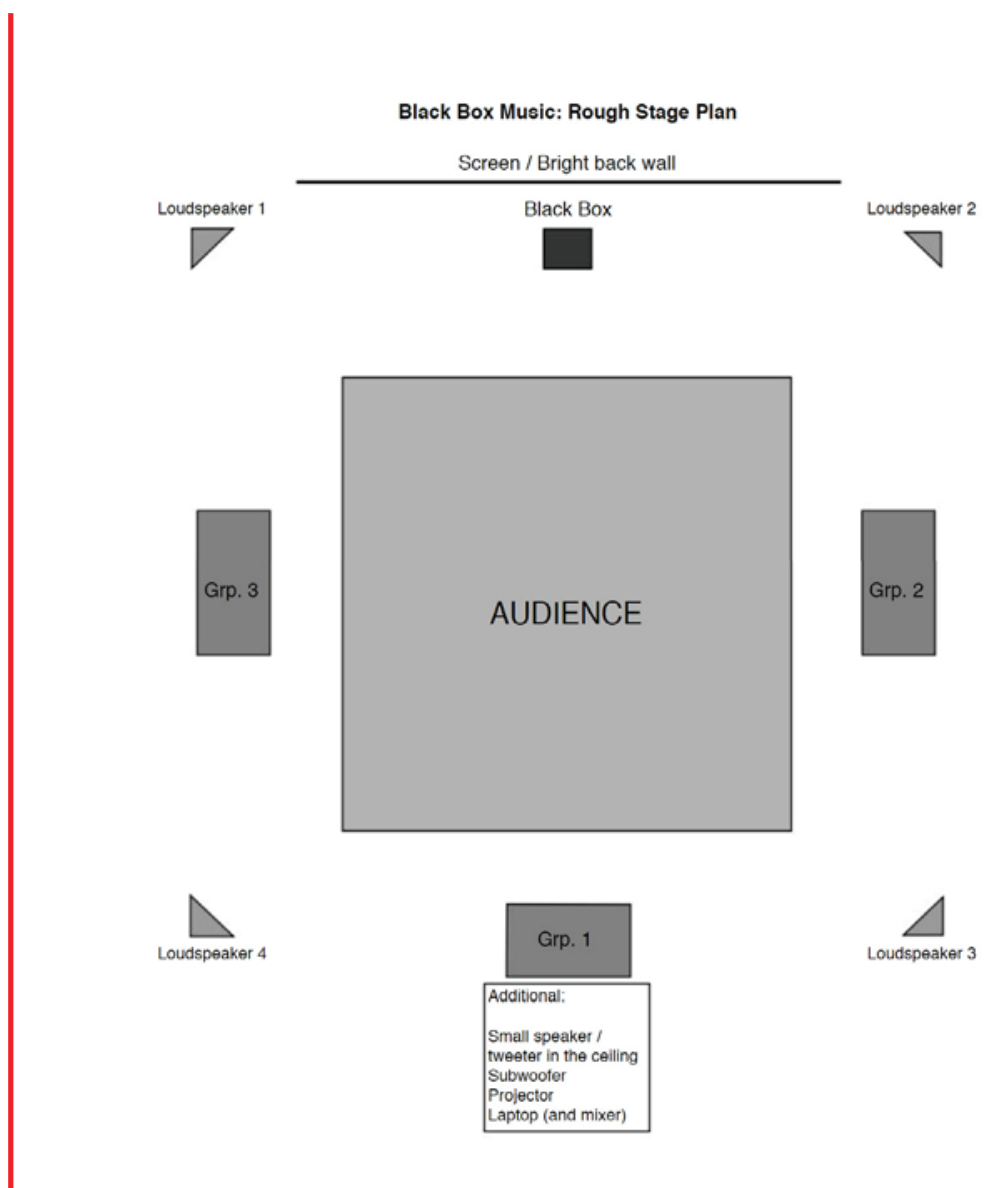

Fig. 1. Simon Steen-Andersen, Black Box Music, rough stage plan. ${ }^{9}$

Steen-Andersen amplifies the visual element by projected a magnified image and showing only the soloist's hands, which makes this figure seem unreal. The soloist's role is, in a way, a variation on classical conducting, since it does include gestures traditionally performed by the conductor such as beat patterns and indicating the onset of sound. These gestures, however, are juxtaposed with others known from everyday non-verbal communication as well as with hand signals belonging to the sign language.

The gestures may be divided into several categories:

9 S. Steen-Andersen, introduction to the score.... 
- emblems, that is, gestures independent of speech, but possessing precisely defined meanings. In this case they indicate numbers, approval (thumbs up), the victory sign (the index and middle fingers form a ' $\mathrm{V}$ '); ${ }^{10}$

- illustrative signs, that is, speech-dependent gestures related to verbal communication, such as the sports sign for 'time out' (right hand placed vertically, the left hand placed horizontally on the right);

- signs for individual letters taken from sign language, illustrated with photographs in the introduction to the soloist's part. Those that recur are indicated by symbols in the score. ${ }^{11}$

The main idea of Black Box Music is to reunite sound with gesture using the above-described audiovisual technique. Music, an art abstract by nature, ${ }^{12}$ is linked here to concrete gestures which have their unequivocal meanings in Western culture. This justifies the use of the term 'music object' rather than interpreting this setup as a visual imitation of the musical layer.

Section one, Ouverture, begins with a sequence of the curtain rising, lights going on, then a tutti chord, followed by a hush-up, lights going off, and the curtain being drawn. The soloist gradually introduces more and more gestures, invariably linked to sound, and begins to build a kind of audiovisual narration. As the composer explains, the procedure consists in 'taking some kind of natural consequence of that gesture and then trying to find a sound for it ${ }^{1}{ }^{13}$ In this case, the natural consequence of the given gesture is the gesture that follows, visually most closely related to the previous one, and selected from the repertory defined in the score. Thus, after the movement symbolising a phone call ('PHONE'; see Fig. 2, gesture of picking up the phone ${ }^{14}$ ), there comes the gesture for 'HANG UP' (Fig. 3, gesture of hanging up ${ }^{15}$ ), while thumbs down can easily come after thumbs up since all it takes to move from one to the other is turn the hand without moving the fingers.

10 'Emblem', in Oxford English and Spanish Dictionary, https://www.lexico.com/ definition/emblem, accessed 10 Apr. 2021.

1 S. Steen-Andersen, Black Box Music (score), https://issuu.com/edition-s/docs/ black_box_music/3, accessed 10 Apr. 2021.

12 H.H. Eggebrecht, Understanding Music. The Nature and Limits of Musical Cognition, tr. by Richard Evans (Routledge: London, 2010).

13 Simon Steen-Andersen - A musical approa[c]h..., 159' oo" - 159' 10".

14 S. Steen-Andersen, Black Box Music (editor's materials).

15 S. Steen-Andersen, Black Box Music (editor's materials). 


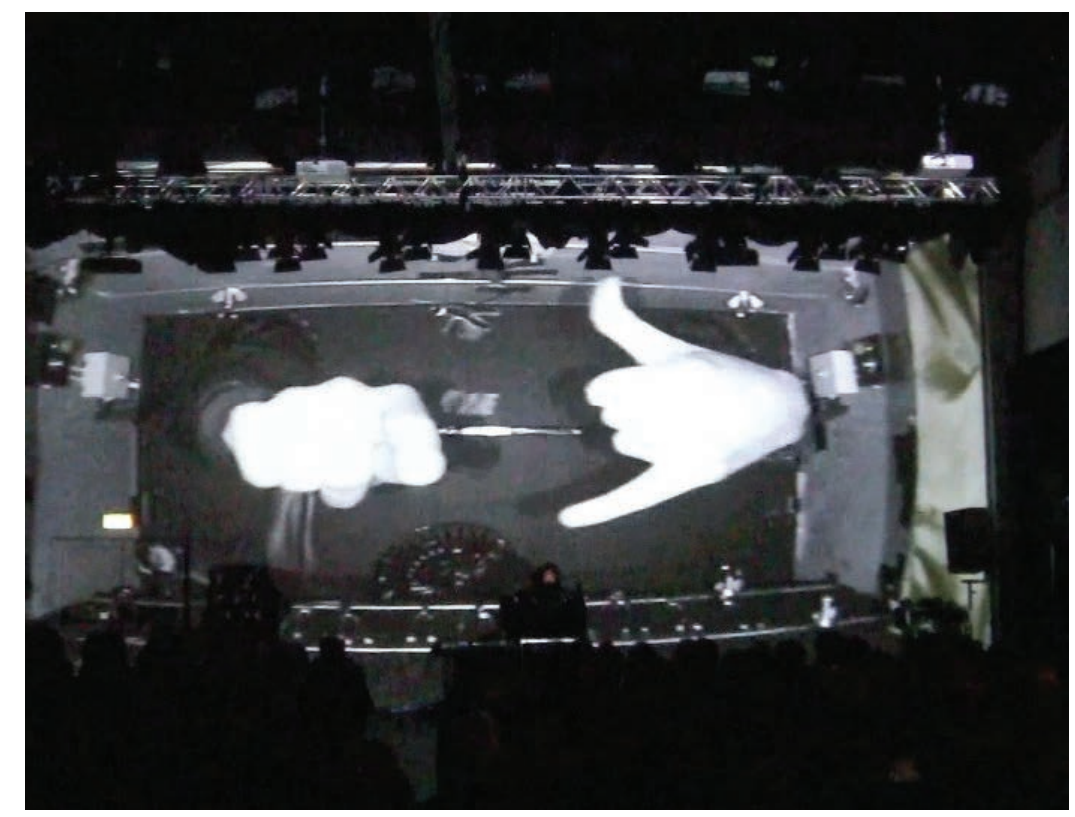

Fig. 2. Simon Steen-Andersen, Black Box Music, gesture of picking up the phone.

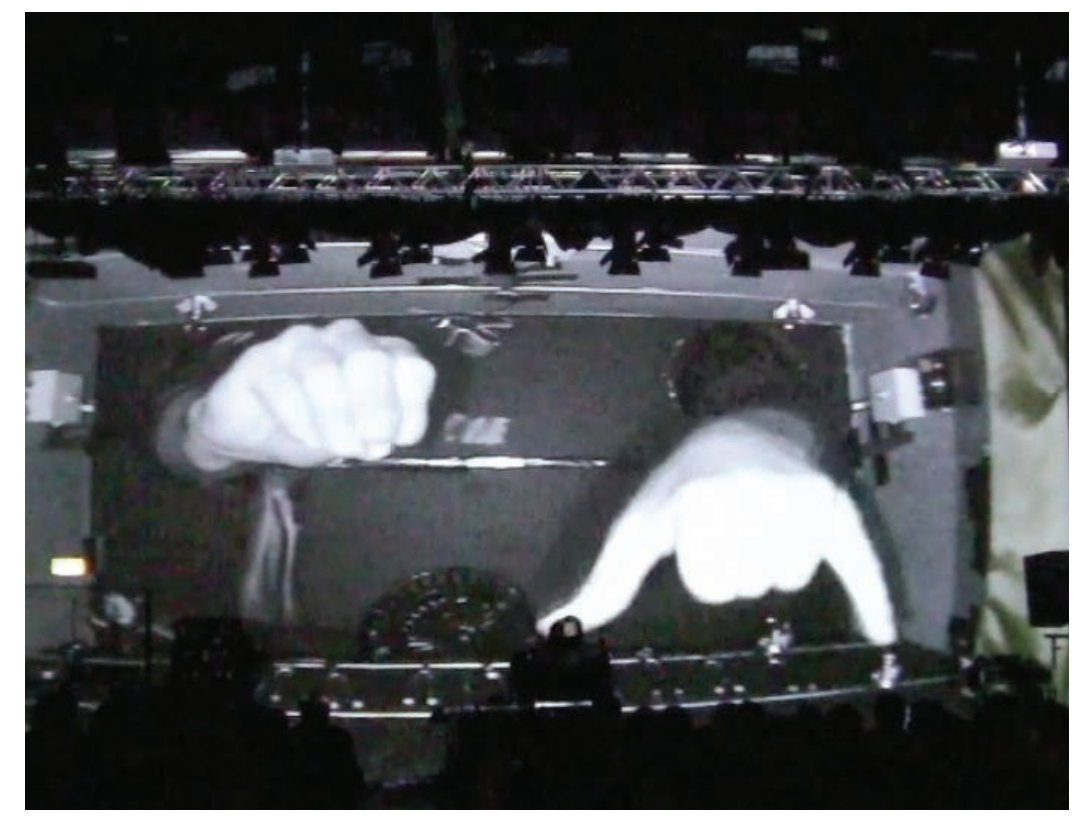

Fig. 3. Simon Steen-Andersen, Black Box Music, gesture of hanging up. 
Gestures also control the topophonic aspect of the composition since the direction of the hand's movement points to the group of instruments responsible for producing the sound compatible with the given gesture. While beating triple time, the soloist's hand moves left-right-up, thus activating in succession the instrumental groups situated to the left of, to the right of, and behind the audience. Gradually the relations between gestures become more and more obvious, so that the whole takes on a progressively choreographic character. From time to time, however, the composer breaks the rules in order to, as he puts in, 'establish a logic, repeat it so many times until you forget it in a way, and then start bending it', using a consonance to bring out a dissonance. ${ }^{16}$ This is why after a series of visually logical and correlated gestures there comes another one consisting of apparently unconnected gestures which, for instance, use the successive degrees of a musical scale as their corresponding sounds. This again directs our attention towards the auditory aspect of the 'spectacle'. The parts of the orchestra and the conductor likewise begin to disintegrate, in imitation of a concert situation when the conductor is perceptibly not synchronised with the orchestra. The composer first provides the spectators with a context through multiple repetitions of a tutti chord indicated by the conductor, and then gradually delays the orchestra's reaction until the orchestra eventually takes over the initiative and the situation is reversed.

The central section is slower and more tonal. Various objects begin to appear in the box, including microtonal tuners with the successive frequencies of $442 \mathrm{~Hz}, 392 \mathrm{~Hz}, 329.6 \mathrm{~Hz}, 523.25 \mathrm{~Hz}, 466 \mathrm{~Hz}$, $415 \mathrm{~Hz}, 435 \mathrm{~Hz}, 440 \mathrm{~Hz}$, and $443 \mathrm{~Hz}$. Through an appropriate use of articulations and dynamics (accents, crescendo dal niente), the instrumental ensemble imitates the sound of the tuning forks, which are made to vibrate by being hit against the base and sides of the box. The tempo calms down; the rhythmic pulsation of the instruments relieves the tension, which prepares the foundations for section three. In the interval between the sections, the composer experiments with the scheme of a classical symphonic concert, making the musicians tune their instruments in a staged fashion until a conductor's baton appears on the screen as a sign from Steen-Andersen's soloist-conductor.

16 Simon Steen-Andersen - A musical approa[c]h..., 2 12'01" - 2 12'09". 
The finale brings a change. Having exploited a certain pool of gestures, the soloist begins to explore the acoustics of the empty box by knocking on its base and sides. Finger snapping in various rhythmic configurations inaugurates a dialogue with the instrumental groups. The soloist also begins to build his own sound installation by stretching rubber bands on hooks previously attached to the base of the box and constructing something like a string instrument. More objects come into the box, one by one: plastic cups, a fan, pieces of paper, a fabric strip, and balloon, hanging on pieces of string and together making up one 'music machine', which works until the box is packed full of objects. ${ }^{17}$ The composer describes the finale as follows: 'It's very festive [...]" but due to the excess of objects 'in the end it kind of collapses in festivity, in a big anti-climax'. ${ }^{18}$ The last act of this spectacle thus leaves us with the image of a useless sound installation.

\section{Sound Objects in Simon Steen-Andersen's Works and Pierre Schaeffer's Acousmatic Listening}

Though Steen-Andersen distances himself from direct inspirations in his works, his audiovisual explorations fit very well into Pierre Schaeffer's concept of new ways of listening, and acousmatic listening in particular. As a composer, leading theorist of the music listening experience, radio announcer and sound engineer, Schaeffer (1910-1995) was especially interested in the influence of the radio and music recording industry on sound reception. ${ }^{19}$ In his work Traité des objets musicaux, Schaeffer distinguished three listening modes:

1. Causal listening - its main objective is to define the cause (or source) of sound on the basis of its qualities; it is an attempt to establish what or who produces the sound, where it comes from, how it behaves, etc.

2. Semantic listening - is responsible for decoding and interpreting messages using a key such as spoken language or sound codes.

\footnotetext{
S. Steen-Andersen, Black Box Music (score). Simon Steen-Andersen - A musical approa[c]h..., 2 17'05" - 2 17'16”.

19 P. Schaeffer, 'Acousmatics', in Ch. Cox, D. Warner, eds, Audio Culture. Readings in Modern Music (2004), 76-81.
} 
3. Reduced or acousmatic listening: 'Listening for the purpose of focusing on the qualities of the sound itself (pitch, timbre, etc.), independent of its source or meaning. ${ }^{20}$

Schaeffer's acousmatic concept is probably routed in phenomenology, which attempts to describe the object without reference to its cause. "Phenomenology disregards the traditional philosophical distinctions between "subject" and "object," "appearance" and "reality" and instead attempts simply to describe the contents of experience without reference to its source or subjective mode (e.g. dreaming, waking, etc.). ${ }^{21}$

The term 'acousmatic' (Fr. acousmatique) is derived from the Greek

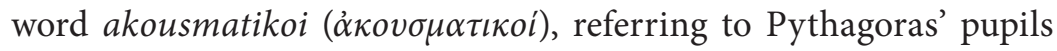
who would listen to their master deliver his lecture from behind a veil or screen, so that only his voice could reach them. This opened their minds up to a new way of perceiving sound. According to Schaeffer, this effect can be achieved nowadays by using modern technical solutions; the Pythagorean veil has been replaced by the radio. At the same time, the acousmatic method provides us with access to 'sound objects', which are the objects of acousmatic listening. ${ }^{22}$ Schaeffer distinguishes four main traits of sound objects:

1. A sound object can be distinguished from the instrument which produces the given sound. As he explains,

It is obvious that when we say 'That's a violin' or 'That's a creaking door,' we are alluding to the sound emitted by the violin, to the creaking of the door. But the distinction we would like to establish between the instrument and the sonorous object is even more radical: if someone plays us a tape which records a sound whose origin we are unable to identify, what are we hearing? Precisely what we are calling a sonorous object, independent of any causal reference, which is designated by the terms sonorous body, sonorous source or instrument.

2. The magnetic tape is not a sound object because the tape is merely the carrier of that object. The presence of the object is associated with our subjective perception. It only acquires sense and meaning at the moment when it is registered and interpreted by the listener's

20 M. Chion, Audio-Vision. Sound on Screen (1990), 223.

${ }_{21}$ Ch. Cox, D. Warner, introduction to Schaeffer, 'Acousmatics', 76.

${ }^{22}$ Schaeffer, 'Acousmatics', 79. 
ears. Acting on the tape physically (for instance, cutting it) does not change the object, since it 'is nonetheless contained entirely in our perceptive consciousness'. ${ }^{23}$

3. The same tape may comprise a number of different sound objects. According to Schaeffer, manipulating the tape does not modify the object itself, but rather creates other objects out of it. The composer also accepts the correlation between the manipulations to which we subject the tape and the perception of the object:

Suppose, for example, that we listened to a sound recorded at normal speed, then slowed down, then again at normal speed. The sloweddown portion, acting like a magnifying glass in relation to the temporal structure of the sound, will have allowed us to discern certain details - of grain, for example - which our listening, thus alerted and informed, will rediscover in the second passage at normal speed. We must let ourselves be guided here by the evidence, and the very way we have had to formulate our supposition dictates the response: it is indeed the same sonorous object, subjected to different means of observation, that we are comparing to itself, original and transposed. But what makes it one and the same object is precisely our will to comparison $[\ldots] .^{24}$

4. A sound object is not a state of the mind. ${ }^{25}$ Schaeffer emphasises the subjective character of object perception. This, however, does not preclude the possibility of analysing and describing the object:

To avoid confusing it with its physical cause or a 'stimulus,' we seemed to have grounded the sonorous object on our subjectivity. But - our last remarks already indicate this - the sonorous object is not modified for all that, neither with the variations in listening from one individual to another, nor with the incessant variations in our attention and our sensibility. Far from being subjective (in the sense of individuals), incommunicable, and practically ungraspable, sonorous objects, as we shall see, can be clearly described and analyzed. We can gain knowledge of them. ${ }^{26}$

23 Schaeffer, 'Acousmatics', 79.

24 Schaeffer, 'Acousmatics', 80.

25 Schaeffer, 'Acousmatics', 81.

26 Schaeffer, 'Acousmatics', 81. 
Steen-Andersen's understanding of the sound object has many features in common with the way it was defined by Pierre Schaeffer. Steen-Andersen claims: 'even my purely instrumental music has always been kind of electronic', which is owing to his 'approach to acoustic music as sound, and also an attempt to get away from the identity of individual instruments. ${ }^{27}$ In Black Box Music, this manifests itself in the division of instruments into groups and blending their sound, in using similar articulations, playing in unison, and dynamics ranging from fortissimo to fortissimo possibile. The composer avoids 'noise' as a direct effect aiming to attract attention. Besides, a type of sound perceived by audiences as unpleasant effectively bars the composition from entering the mainstream. Nevertheless, he understands the 'sound object' itself as the visual layer which is an integral part of the musical one, inseparable from it for as long as our eyes remain open. Steen-Andersen comments that the concept of integrating elements belonging to different categories of perception need not be limited to hearing and sight but may also be extended so as to include other senses. $^{28}$

The acousmatic method to some extent necessitates the presence of the visual component, be it the Pythagorean veil or a loudspeaker. The subversive situation in Black Box Music incorporates and in a way presupposes all of Schaeffer's listening modes. By creating a topophonically arranged and speaker-transformed instrumental layer, the composer puts the audience's causal listening abilities to the test. The same effect is achieved through blending (unifying) the instrumental colours and concealing the relations between the ensemble's playing and the position of the hands in the box. Semantic listening is also present in the motion-and-sound narrative of the work, despite the lack of any verbal content. Interpretation of the given gesture takes place in conjunction with the sound that is identified with that gesture. For instance, the sound of the phone ringing is associated with the gesture of picking up the phone, clearly distinguished from the movement which represents 'hanging up'.

Acousmatic listening is present, first and foremost, in the above-discussed technique of blending instrumental sound. The role of the 'Pythagorean veil' is played in Black Box Music by the

${ }_{27}$ Simon Steen-Andersen - A musical approa [c] $]$..., 1'46" - 2'15".

28 Simon Steen-Andersen - A musical approa[c]h..., 28'oo" and ff. 
screen with the projection of the soloist's hand movements. Though our intuition might suggest that the projection only reinforces causal listening, it in fact creates one more, additional visual layer which camouflages the actual source of the sound. A similar technique has been applied in numerous productions of Wolfgang Amadeus Mozart's The Magic Flute, or even at contemporary pop music concerts. In Act Two of Mozart's opera, Papageno the bird-catcher is looking for his beloved Papagena, and, having not found her, in despair makes up his mind to hang himself. Three child-spirits appear just in time to remind him of the magic silver bells he possesses. Their sound brings Papagena to the stage, and this scene is followed by a triumphant finale..$^{29}$ In many stage productions of the opera such as the one presented in 2006 at the Metropolitan Opera ${ }^{30}$ and in Miloš Forman's film Amadeus, ${ }^{31}$ the part of the bells is actually performed by a celesta hidden in the orchestra pit, whereas the bells only serve as a stage prop.

Another example is the playback technique frequently used by pop artists while performing songs accompanied by complex choreographies, which make simultaneous singing difficult. In this case, the pre-recorded soundtrack comprising the vocal part is played back from the speakers, while the singer only moves his or her lips, thus acting out a performance of the piece in real time. During the 2011 California Dreaming concert tour, US singer Katy Perry imitated playing the recorder in one of the songs but was exposed since her movements were evidently at odds with the flute's melody.32 The anecdotal end of this episode can be interpreted in the context of audiovisuality. The situation is similar here to that described by Steen-Andersen. The listener, who normally does not expect the artist to use playback during a concert, will take it as a jarring note; even more so if the visual and auditory layers no longer correspond to each other.

29 P. Kamiński, Tysiąc i jedna opera (2015), 1052.

30 Metropolitan Opera, The Magic Flute (2006), https://www.youtube.com/ watch? $\mathrm{v}=\mathrm{qFolidudY_{74 }}$, accessed 12 Apr. 2021.

${ }_{31}$ M. Forman, excerpt from Amadeus, 1974, https://www.youtube.com/watch?v=3glswAQNR7c, accessed 12 Apr. 2021.

$32 \quad A B C$ News, 'Katy Perry Flute Fail: Singer Accidentally Reveals She's Not Really Playing Recorder', https://www.youtube.com/watch?v=wbqFMgdSeGs, accessed 12 Apr. 2021. 


\section{Conclusions}

The visual factor has always played a very important role in music. Intermedia art perception has invariably been part of culture from ancient syncretism to the opera to film soundtracks. In all these genres, however, the musical and visual layers can be separated from each other. The opera as a predominantly musical form still retains its artistic value when listened to as a recording, while its various productions may be considerably different in visual terms. In films, though music is their integral part and frequently provides an emotional context, it is still in many cases not directly related to any specific movie sequence. For instance, Ludwig van Beethoven's Symphony No. 9 in D minor Op. 125 can be heard in many different films, but this fact does not have any impact on the original music content.

The situation is reversed, however, in the works of Simon Steen-Andersen. Black Box Music is a perfect research area for a discussion of audiovisuality, the role of modern technologies in the composition process and in music theatre, the relations between the conductor and the orchestra, topophonics, and many other aspects of the topic. Most of all, Steen-Andersen's composition impresses the listener/viewer with the complexity of experience. The work's carefully designed structure, which combines the achievements of previous generations of composers with new technologies, is an example of a comprehensive intermedia event whose every component has its precisely defined place and function. The absolute integration of visual and musical elements in this work makes it possible to interpret it on many levels and opens up completely new possibilities for music work perception and conceptualisations of audiovisuality.

The question remains open whether Simon Steen-Andersen's output should be viewed as the summary and closing achievement in the field of interactions between visual and auditory elements, or whether, conversely, his output paves the way for further explorations of audiovisual interrelations. 


\section{Bibliography}

\section{References}

$A B C$ News, 'Katy Perry Flute Fail: Singer Accidentally Reveals She's Not Really Playing Recorder', https://www.youtube.com/watch?v=wbqFMgdSeGs, accessed 12 Apr. 2021.

Classic Voice 212 (2017), http://www.classicvoice.com/riviste/classic-voice-digital/classic-voice-212-digitale.html, accessed 14 June 2020. Chion, M., Audio-Vision. Sound on Screen (Columbia University Press: New York Chichester, 1990).

Chłopecki, A., 'Wizualizacja', in Dziennik ucha. Stuchane na ostro (PWM: Kraków, 2013; Wydawnictwo Krytyki Politycznej: Warszawa, 2013).

Cox, Ch., Warner, D. eds, Audio Culture. Readings in Modern Music (Bloomsbury Publishing: London, 2004).

Eggebrecht, H.H., Understanding Music. The Nature and Limits of Musical Cognition, tr. by Richard Evans (Routledge: London, 2010).

Forman, M., excerpt from the film Amadeus (1974), https://www.youtube. com/watch? $v=3$ glswAQNR7c, accessed 12 Apr. 2021.

Holmboe, R., 'Out of the Box', liner notes for a DVD, Dacapo Records, https://www.dacapo-records.dk/en/recordings/steen-andersen-black-box-music, accessed 10 Apr. 2021.

Kamiński, P., Tysiąc i jedna opera (PWM: Kraków, 2015).

Metropolitan Opera, The Magic Flute (2006), Papageno's aria, https:// www.youtube.com/watch? $\mathrm{v}=\mathrm{qFolidudY}$ 74, accessed 12 Apr. 2021.

Kowalska-Zając, E., Zobaczyć muzyką, Notacja polskiej partytury wspótczesnej (Akademia Muzyczna im. Grażyny i Kiejstuta Bacewiczów w Łodzi: Łódź, 2019).

Oxford English and Spanish Dictionary, Thesaurus, and Spanish to English Translator, https://www.lexico.com.

Schaeffer, B., Mały informator muzyki XX wieku (PWM: Kraków, 1975).

Schaeffer, B., Muzyka XX wieku. Twórcy i problemy (Wydawnictwo Literackie: Kraków, 1975).

Schaeffer, P. 'Acousmatics', in Ch. Cox, D. Warner, eds, Audio Culture. Readings in Modern Music (Bloomsbury Publishing: London, 2004), 76-81. 
Steen-Andersen, S., Black Box Music (editor's materials), introduction to the score (2020), https://www.edition-s.dk/music/simon-steen-andersen/black-box-music, accessed 10 Apr. 2021.

Steen-Andersen, S., Festival TACEC 2018, https://www.youtube.com/

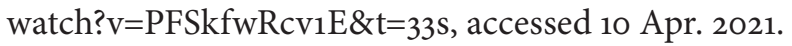

Steen-Andersen S., A musical approa[c]h to audio/visual composition: Implicit $A V$ aspects of musical performance, $A V$-objects and musical excuses..., https://www.youtube.com/watch?v=YGfKe99aa7s, , accessed 10 Apr. 2021. 